\title{
Os conteúdos de Planejamento e Gestão em Saúde a partir do uso de metodologias ativas de ensino- aprendizagem: a opinião dos estudantes
}

Tarsila Teixeira Vilhena Lopes, Leonardo Carnut, Lúcia Dias da Silva Guerra, Celso Zilbovicius, Afonso Luís Puig Pereira

\section{Resumo}

Introdução: Os conteúdos de Planejamento e Gestão em Saúde para especializandos na área da Saúde Coletiva constituem um núcleo de 'saberes fundamentais' para todos os profissionais que desejam se dedicar a essa área. Assim, já é bem consolidada a necessidade de introduzir os conteúdos sobre os métodos de planejamento e de modelos de gestão em saúde, identificando seus desafios, estruturação e consolidação enquanto subárea da Saúde Coletiva, assim como o aprofundamento sobre o planejamento enquanto método gerencial do ponto de vista prático. Também, constitui-se como saber essencial dessa subárea algumas generalidades sobre a natureza dos serviços de saúde que são fundamentais para análise organizacional do futuro sanitarista, portanto, pode-se dizer que um rol de conhecimentos comuns precisam ser construídos por profissionais que advém de áreas profissionais bastante distintas. Nesse sentido, alcançar a construção do 'comum' a partir da interprofissionalidade faz-se um desafio necessário no processo de ensino- aprendizagem com esses tipos de conteúdos, haja vista a necessidade de produção de sentido e de cada um deles a partir do repertório teórico de cada uma das profissões da saúde interessadas nesse tema. Portanto, aposta-se que as metodologias ativas de ensino- aprendizagem, por suas características inerentes podem ajudar na condução de um 'processo de aprendizagem' dos estudantes que proporcionem um pensamento mais interdisciplinar sobre a sua prática e que favoreça o alcance dos objetivos preconizados para essa especialização. Objetivo: Assim, este estudo visou descrever a opinião dos estudantes de especialização em Saúde Pública sobre a aprendizagem dos conteúdos de Planejamento e Gestão em Saúde a partir do uso de metodologias ativas de ensino-aprendizagem. A intenção dessa pesquisa foi traçar um diagnóstico inicial da introdução das metodologias ativas considerando a Especialização em Saúde Pública um espaço multiprofissional de produção do comum e como cenário de pluralidade de perfis que proporciona desafios na aprendizagem desses conteúdos. Metodologia: Para o alcance deste objetivo, desenhouse um percurso metodológico baseado em uma pesquisa-ação, qualiquantitativa, com foco na investigação de percepção vivencial dos discentes sobre uma estratégia didática adotada. $\mathrm{O}$ cenário pedagógico foi o módulo de 'Planejamento e Gestão em Saúde', com carga horária total de 40 horas, ministrada na Especialização em Saúde Pública, do Campus Arcoverde da Universidade de Pernambuco (UPE) em outubro de 2014 e tendo dezenove (35) estudantes como sujeitos partícipes dessa atividade. Como se tratou de um curso orientado para profissionais da Regional de Arcoverde, o processo de planejamento levou em consideração a realidade de três municípios dessa regional para condução dos trabalhos práticos de planejamento: Arcoverde (município sede da regional), Buíque e Venturosa. Os dados que subsidiaram o planejamento foram aqueles disponíveis no Relatório Anual de Gestão (RAG) de cada um dos municípios, disponíveis no Sistema de Apoio ao Relatório de Gestão do Sistema Único de Saúde (SARG-SUS). Assim, a disciplina teve como conteúdo programático: Introdução ao Planejamento e Gestão em Saúde; Métodos de Planejamento em Saúde; Planejamento Estratégico Situacional (PES); Fundamentos da Gestão em Saúde. Deste conteúdo, derivou-se o Objetivo Geral (OG) da disciplina, que constituiu-se em compreender os conceitos e métodos de planejamento e gestão, propiciando condições para criar alternativas aos problemas existentes no processo de trabalho em saúde; e dentre os Objetivos Específicos (OE) que 
ISSN 2179-6750

compunha a disciplina estavam: (1) Identificar os principais desafios na construção do conhecimento prático advindos da prática em planejamento e gestão em saúde; (2) Aplicar um Método de Planejamento em Saúde para um caso específico sob estudo, e (3) Discutir os elementos fundamentais relacionados à natureza dos serviços de saúde que são essenciais à gestão. Ao decorrer do módulo, os residentes trabalharam estes conteúdos através de uma abordagem pedagógica mista baseada em dois momentos de Leituras Coletivas em Pequenos Grupos de Aprendizagem, Aula Expositiva- Dialogada, Mapas Conceituais, Oficina de Prática de Planejamento em Saúde e Leitura Dirigida. Ao final do módulo, aplicou-se um formulário como perguntas relativas ao alcance dos Objetivos Específicos acima citados como também em relação ao uso das Metodologias Ativas empregadas. As respostas eram fechadas em formato de uma Escala Likertt e ao término da coleta, os dados foram analisados através de medidas de tendência central e descritos em função de seus percentuais. Resultados: Após a análise dos dados, identificou- se que em relação à aprendizagem com uso de Leituras Coletivas os estudantes relataram que a Leitura coletiva 1 foi "Ótima" 25,7\% (9); "Boa" 60,0\% (21); "Regular" 2,9\% (10); "Ruim" 5,7\% (2) e "Não respondeu" 5,7\% (2). No segundo momento de Leitura Coletiva, os estudantes consideraram a estratégia didática "Ótima" 40,0\% (14); "Boa" 45,7\% (16); "Regular" 5,7\% (2); "Ruim" 2,9\% (1) e "Não respondeu" 5,75\% (2). Sobre a Aula expositiva- dialogada, os estudantes a consideraram "Ótima" 48,6\% (17); "Boa" 40,0\% (14); "Regular" 2,9\% (1) e "Não respondeu" 8,6\% (3). Sobre a utilização dos Mapas Conceituais, os estudantes consideram a estratégia didática "Ótima" 62,9\% (22); "Boa" 25,7\% (9); "Regular" 5,7\% (2); "Ruim" 2,9\% (1) e "Não respondeu" 2,9\% (1). No que se refere à Oficina de Prática de Planejamento em Saúde, os estudantes consideraram como "Ótima" 71,4\% (25) e "Boa" 28,6\% (10). Por fim, a estratégia da Leitura Dirigida foi considerada pelos estudantes como "Ótima" 54,3\% (19); "Bom" 40,0\% (14); "Regular" 2,9\% (1) e "Ruim" 2,9\% (1). Em relação ao alcance dos Objetivos Específicos (OE) através das metodologias ativas supracitadas, os especializandos consideraram que, o Objetivo Específico 1 (OE-1) foi alcançado de forma "Ótima" 25,7\% (9); "Boa" 57,1\% (20); "Regular" 14,3\% (5) e "Péssimo" 2,9\% (1). Já o alcance do OE-2 foi considerado "Ótimo" 28,6\% (10); "Bom" 57,1\% (20) e "Regular" 14,3\% (5). Por fim, o alcance do OE-3 foi considerado "Ótimo" 45,7\% (16); "Bom" 42,9\% (15); "Regular" 8,6\% (3); "Péssimo" 2,9\% (1). Conclusões: Neste contexto conclui-se que, de uma maneira geral, os conteúdos sobre Planejamento e Gestão em Saúde foram bem apreendidos pelo uso das metodologias ativas empregadas. Houve uma ênfase clara no aprendizado dos conteúdos que se relacionam à discussão da realidade e os elementos fundamentais relacionados à natureza dos serviços de saúde que são essenciais à gestão (OE-3). É possível considerar que o uso das metodologias ativas pode ter sido a promotora da interprofissionalidade necessária para que esse objetivo tenha sido ao mais bem alcançado segundo a avaliação dos estudantes. Em relação às metodologias ativas adotadas nessa experiência pedagógica parece que os estudantes ainda se reportam à prática de planejamento como a mais importante de todas, secudarizando o papel dos demais métodos usados. Em que pese a relevância da mescla de métodos na tentativa de contemplar os diferentes perfis de aprendizagem, os estudantes ainda valorizam mais a prática das atividades do que os métodos pedagógicos remetendo à instrumentalidade/operacionalidade que permeia a formação nas profissões de saúde em geral.

Descritores: Internato e Residência, Ensino, Educação Superior, Docentes 